\title{
Editorial
}

\section{Las lecciones de las elecciones del 88}

Por quinta vez desde 1982 el pueblo tuvo elecciones para elegir a sus nuevos gobernantes. Por quinta vez estas han tenido lugar en un clima de guerra que ya dura más de 8 años y dentro de un contexto de crisis generalizada del sistema socio-económico político e institucional. Por igual número de veces se intentó hacer de las elecciones la única vía posible para la solución de los graves problemas nacionales. $Y$ de nuevo el resultado del proceso ha agudizado más la crisis, ha acelerado y profundizado aún más las contradicciones entre las diversas fuerzas sociales, ha polarizado radicalmente a los diversos sectores de la sociedad. Por quinta vez se ha demostrado que las elecciones por sí mismas no pueden convertirse en principio de solución para los graves problemas del país hasta el punto de poner en duda el limitado proceso democrático que se ha puesto en marcha en el país. No cabe duda que las elecciones son una parte constitutiva del juego democrático, pero dada las condiciones del país éstas se han revertido en contra de él. Así se demostró en la sampaña y los hechos que siguieron al anuncio de los resultados del proceso. Las perspectivas que se vislumbraron no son nada alagueñas para El Salvador. La guerra y las contradicciones políticas entre los partidos políticos que participaron en las pasadas elecciones, aunado a la grave crisis económica sin precedentes en que se debate esta sociedad, pueden llevar, y de hecho estan conduciendo, a una debacle institucional de gravísimas consecuencias para la vida del país.

Sin embargo, las pasadas elecciones del 20 de marzo presentó rasgos y elementos nuevos que son necesarios analizar y destacar para una mejor comprensión del proceso, y que hicieron de este proceso diferente, aunque los actores políticos principales sigan siendo los mismos.

En primer lugar, la propaganda electoral se concentró en el desprestigio y la descalificación entre los partidos más importantes y ma- 
yoritarios: ARENA y el PDC. Las numerosas acusaciones de corrupción e incapacidad que gravitaron sobre la Democracia Cristiana fueron acompañadas por igual número de acusaciones sobre ARENA de ser un partido de secuestradores y asesinos culpables de la represión en el país. De esta manera, la campana giró en torno a calumnias, acusaciones de todo tipo y nada de propuestas serias. Tan vacia y falta de contenido fue la campańa que tanto la Iglesia Católica como el Alto Mando de la Fuerza Armada, tuvieron opiniones desfavorables sobre la dinámica que había seguido la misma. Quizás por ese motivo la campaña de mutuas acusaciones se detuvo un poco en el intermedio, pero para volver con más fuerza y culminar al final a pocos dias antes de la votación con el escándalo de CONARA, en donde se acusó a altos dirigentes de la Democracia Cristiana de malversación de varios millones de colones. Tal y como se desarrolló la campana y por las "propuestas" que los partidos hicieron, quienes votaron no tenian ninguna altemativa seria para elegir y se terminó por castigar lo que era más evidente: la ineficiente gestión administrativa de la DC.

El proceso nos re-afirmó a los salvadorenos que las elecciones, en el contexto actual, siguen sin aportar nada nuevo a la necesidad urgente de terminar con la actual situación de guerra. Los políticos parece que olvidan la realidad en que vivimos, de alli que las elecciones han salido desprestigiadas como mecanismo de democracia formal después de la dinámica de la campaña.

Aunado a todo 10 anterior, la presencia popular se incrementó durante ese período. Las protestas, marchas, manifestaciones y huelgas fueron abundantes, especialmente en el sector de los empleados públicos. La UNTS se manifestó en contra de las elecciones y condenó la forma en que se había llevado a cabo la campana y llamó a sus bases a no concurrir a las urnas, calificando a las elecciones como una maniobra más del imperialismo en su estrategia contrainsurgente. EI FMLN, por su parte también las calificó como tales y acrecentó sus acciones militares. EI gobierno y el ejército quisieron deslegitimar las acciones del FMLN a través del descubrimiento de un "plan fuego" en el que se pretendia haber develado los planes de la izquierda de boicotear las elecciones. La guerra y el conflicto se agudizaron. El 18 de marzo el FMLN decretó un paro al transporte en todo el territorio nacional que limitó la movilización de la población durante el dia de las elecciones.

En segundo lugar, el resultado que las elecciones arrojó, aunque ya se percibía su tendencia a través de algunas encuestas, modificaciones sustanciales en la correlación de fuerzas políticas entre los agentes políticos más importantes y ha dado lugar a contradicciones, que al momento, parecen paralizar la gestión del Estado y ha provocado un desmoronamiento institucional sin precedentes en la historia del país. La 
Democracia Cristiana había conquistado la mayoria absoluta en la asamblea en las elecciones de 1985, con ello tenía en términos absolutos el control de los aparatos del Estado. Su gestión, sin embargo, se vió deslegitimada por el desgaste que sufrió su proyecto con el agravamiento de la crisis, la continuación de la guerra y la postración económica de las grandes mayorias. En las pasadas elecciones se expresó claramente las frustración del pueblo y el desgaste del proyecto Demócrata Cristiano, que se encontró, en los pasados tres años, con serios obstáculos para su viabilidad, ya porque el proyecto norteamericano de contrainsurgencia no podia fructificar, ya porque no encontró bases sociales sólidas a nivel de la sociedad civil que lo sustentaran, o ya porque sus propios protagonistas han mostrado su gran incapacidad, en cualquier proyecto político. De esta manera, la Democracia Cristiana se presentó a las elecciones completamente dividida a su interior y completamente desgastada y deslegitimada hacia el exterior. Todo ello fue capitalizado por el partido mayoritario de derecha: ARENA. Había que castigar la pésima gestión política de los Demócratas Cristianos porque no solamente fueron incapaces de iniciar un proceso de solución de los graves problemas del país, sino que la crisis se acentuó y los problemas se agravaron aún más. ARENA capitalizó lo que se ha dado en llamar "el voto de castigo" de los salvadorehos que votaron. No se trata pues de un proceso de derechización del electorado, sino de un rechazo a la incapacidad de la DC.

Los resultados de las elecciones muestran muy claramente bo antes dicho. De 930, 749 votos válidos para diputados el PDC captó el $35.1 \%$, ARENA el $48.1 \%$ y el PCN el 8.46. Un resultado totalmente a la inversa de lo que habia sucedido en 1985 , cuando el PDC obtuvo el $52.35 \%$, ARENA $29.7 \%$ y el PCN el $8.36 \%$. De lo anterior resulta que "una masa electoral posiblemente de unos 150,000 votantes ha cambiado de opción, del PDC hacia ARENA". Fueron estos 150,000 votantes que de alguna manera "castigaron" al PDC y no puede interpretarse como una base sólida de ARENA. En cuanto a los consejos municipales, los resultados fueron casi similiares, mientras el PDC ganó 200 alcaldias en las elecciones de 1985, en las elecciones recién pasadas ARENA ganó cerca de 200 alcaldias y 13 cabeceras departamentales.

Pero los resultados de las elecciones también nos arrojan otros interesantes resultados. El número absoluto de votos válidos bajó de 1985 a 1988; en 1985 éstos fueron 965,231 y en 1988 fueron 920,749, baja que resulta acrecentada si le agregamos el incremento natural de la población en edad de votar durante este periodo.

Pero los resultados de las elecciones también nos arrojan otros interesantes elementos a analizar. Si bien es cierto que el número de votantes es un poco mayor en estas elecciones con respecto a las de 
1985, este leve incremento no es compensado con el aumento natural de votantes durante este período. En 1985 el número de votantes fue de 1,107,472 y en 1988 fue de 1,150,934. Si a ello le agregamos que el número de votos válidos permaneció básicamente igual, es fácil concluir que el ausentismo creció y que el número de abstenciones, votos nulos e impugnados también se vió incrementados, estos votos no válidos pasaron del $12 \%$ en 1985 al $19 \%$ en 1988 . Según algunas fuentes, la población electoral en El Salvador se calcula en 3.1 millones, de ellos solamente 2.1 millones lograron empadronarse para formar el registro electoral, de éstos sólo 1,650,000 logró obtener su carnet electoral y, finalmente, sólo 970,400 hicieron efectivo su voto, que representa el $31 \%$ de la población en edad de votar, el resto el $69 \%$, o bien no pudieron hacer efectivo su voto por las deficiencias del registro electoral (que podría ser una minoría) o consideraron que las elecciones no son una real alternativa para resolver los graves problemas del país.

Según los datos anteriores no es demasiado extremo afirmar que las elecciones han ido perdiendo legitimidad como mecanismo dentro de la democracia formal para dirimir las contradicciones dentro de esta sociedad, y cada vez es más claro que mientras no se resuelva el problema de la guerra y se abran verdaderos espacios políticos para otras opciones, las elecciones seguirán siendo un mecanismo formal que obstaculiza el inicio de un verdadero proceso que tienda a la solución de los reales problemas. Una vez más, pues, los salvadoreños hemos entendido que elecciones y guerra es una pésima combinación. 